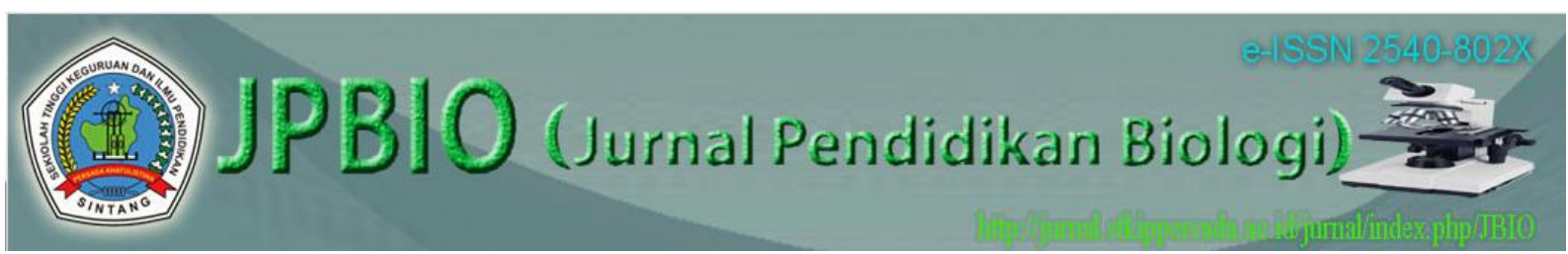

JPBIO (Jurnal Pendidikan Biologi)

Vol. 3 No. 1 April 2018 | $18-25$

ISSN 2540-802x (Online)

DOI: http://dx.doi.org/10.31932/ JPBIO (Jurnal Pendidikan Biologi)

http://jurnal.stkippersada.ac.id/jurnal/index.php/JBIO

\title{
PENGARUH MODEL PEMBELAJARAN STUDENT TEAMS ACHIEVEMENT DIVISIONS TERHADAP KOGNITIF SISWA PADA MATERI SISTEM PERNAPASAN MANUSIA
}

\author{
Agustina Lemaya Dewi ${ }^{1^{*}}$, Hilarius Jago Duda ${ }^{2}$, Markus lyus Supiandi ${ }^{3}$ \\ ${ }^{1}$ Mahasiswa Program Studi Pendidikan Biologi, STKIP Persada Khatulistiwa, Sintang \\ ${ }^{2,3}$ Dosen Program Studi Pendidikan Biologi, STKIP Persada Khatulistiwa, Sintang \\ E-mail: agustinald@gmail.com ${ }^{*}$, hilariusjagod@yahoo.com², msupiandi@gmail.com³
}

Diterima: 17 Januari 2018

Direvisi: 10 Februari 2018 Disetujui: 15 Maret 2018

\begin{abstract}
ABSTRAK
Penelitian ini dilatarbelakangi oleh penerapan model pembelajaran di sekolah masih belum cukup bervariasi, peserta didik tidak memperhatikan penjelasan guru, peserta didik lebih banyak menggunakan kesempatan tersebut untuk bermain dengan temannya atau melakukan aktivitas lain yang tidak berkaitan dengan materi yang sedang diajarkan guru. Tujuan penelitian ini adalah Untuk mengetahui pengaruh model pembelajaran student teams achievement divisions (STAD) terhadap hasil belajar kognitif siswa pada materi sistem pernapasan manusia. Metode yang digunakan dalam penelitian ini adalah metode kuantitatif. Bentuk penelitian yang digunakan yaitu Quasi-eksperimen dengan desain penelitian Nonequivalent Control Group Design. Teknik pengambilan sampelnya menggunakan teknik Sampling Jenuh. Teknik pengumpulan data menggunakan teknik observasi langsung, teknik pengukuran, teknik komunikasi tidak langsung dan teknik studi dokumentasi. Instrument pengumpulan data yang digunakan adalah instrument pengumpul dan instrument pengukur. Instrument pengumpul yang digunakan dalam penelitian ini yakni: silabus, RPP, dan lembar kerja siswa (LKS). Instrument pengukur yang digunakan dalam penelitian ini yakni: lembar observasi, lembar angket respon siswa, soal tes hasil belajar kognitif. Berdasarkan perhitungan kognitif siswa diperoleh nilai rata-rata pretest 38.89 untuk kelas eksperimen dan 35 untuk kelas kontrol serta nilai rata-rata posttest 70.74 kelas eksperimen dan 51 kelas kontrol. Teknik pengolahan data menggunakan Uji t. Uji t digunakan pada data posttest kelas eksperimen dan kontrol yang berdistribusi normal. Hasil dari uji hipotesis data posttest diketahui thitung adalah 6,981 sedangkan $t_{\text {tabel }}$ pada $\alpha=5 \%$ adalah 1,91. Hal ini berarti thitung $>$ $t_{\text {tabel }}(6,981>1,91)$ maka Ha diterima. Disimpulkan bahwa terdapat pengaruh yang signifikan penggunaan Model Pembelajaran STAD Terhadap Kognitif Siswa pada Materi Sistem Pernapasan Manusia.
\end{abstract}

Kata kunci: STAD, kognitif siswa, sistem pernapasan manusia.

\section{ABSTRACT}

This research is motivated by the application of a model of learning in schools is still quite varied, learners do not pay attention to the teacher's explanation, learners are more used the opportunity to play with her friends or doing other activities that are not related to the content 
being taught teachers. The purpose of this study was to determine the effect of learning model student teams achievement divisions (STAD) the cognitive achievement of students on the material of the human respiratory system. The method used in this research is quantitative method. Research form used is Quasi-experimental research design Nonequivalent Control Group Design. The technique of taking the sample using saturated sampling technique. Data collection techniques using direct observation techniques, measurement techniques, indirect communication techniques and engineering documentation. Instrument Data collection is an instrument collector and instrument gauges. Instrument collectors used in this study are: syllabus, lesson plans, and student worksheet (LKS). Instrument gauges were used in this study are: the observation sheets, sheet student questionnaire responses, cognitive learning about the test results. Based on the calculation of cognitive learning outcomes of students obtained an average value of 38.89 for the class pretest experiment and 35 for the control class as well as the average value of 70.74 posttest experimental class and control class 51 . Data processing techniques using $t$ test. $t$ test used in data posttest experimental class and control the normal distribution. The results of hypothesis testing posttest data is known thitung is 6.981 while $t$ table at $\alpha=5 \%$ was 1.91 . This means thitung $>t$ table $(6.981>1.91)$, the $\mathrm{Ha}$ accepted. It was concluded that there is significant influence use Learning Model STAD Cognitive Learning Outcomes Students Against the Human Respiratory System material.

Keywords: STAD, cognitive student, human respiratory system.

\section{PENDAHULUAN}

Pendidikan merupakan faktor yang sangat penting dalam kehidupan manusia. Pendidikan merupakan proses dalam pembangunan manusia untuk mengembangkan dirinya agar dapat menghadapi segala permasalahan yang timbul pada diri manusia itu sendiri.

Dalam Undang-undang No. 20 Tahun 2003, tentang Sistem Pendidikan Nasional dengan isinya sebagai berikut: "pendidikan dapat diartikan sebagai usaha sadar dan terencana untuk mewujudkan suasana belajar dan proses pembelajaran agar peserta didik secara aktif mengembangkan potensi dirinya untuk memiliki kekuatan spiritual keagamaan, pengendalian diri, kepribadian, kecerdasan, akhlak mulia, serta keterampilan yang diperlukan dirinya, masyarakat bangsa dan negara".

Berdasarkan hasil observasi di Sekolah Menengah Pertama Negeri 7 Dedai pada tanggal 04 Agustus 2016, faktor yang dapat mempengaruhi tingkat kognitif peserta didik adalah penerapan model pembelajaran yang masih bersifat konvensional, pemahaman peserta didik yang masih kurang, dan hasil kognitif peserta didik yang masih rendah, maka diperlukan suatu model pembelajaran yang lebih efektif dan lebih menekankan pada keaktifan belajar pserta didik.

Keberhasilan yang dapat dicapai peserta didik bukan hanya tergantung pada proses pembelajarannya, tetapi tergantung pula dari peserta didik itu sendiri. Sudjana (2006: 34) mengemukakan bahwa, "hasil belajar yang dicapai peserta didik dan faktor yang datang dari luar peserta didik atau lingkungan". Hasil belajar yang diharapkan meliputi ranah kognitif, ranah afektif, dan ranah psikomotorik.

Menurut Anni (Dimyati dan Mudjiono, 2013: 200) "Ranah kognitif berhubungan dengan kemampuan berpikir kritis, termasuk didalamnya kemampuan menghafal memahami, mengaplikasi, menganalisis, ranah afektif meliputi watak, perilaku, dan ranah psikomotorik mencakup menunjukkan adanya kemampuan fisik". Ranah kognitif terdiri dari enam jenis perilaku sebagai berikut: 1) Pengetahuan (C1), 2) Pemahaman (C2), 3) Penerapan (C3), 4) Analisis (C4), 5) Sintesis (C5), 6) Evaluasi (C6). Adapun ranah kognitif yang digunakan peneliti dalam penelitian ini adalah: pengetahuan (C1), pemahaman (C2) dan penerapan (C3). Pembelajaran dengan model Student Teams Achievement Divisions (STAD) merupakan model pembelajaran dengan cara mengelompokkan siswa berdasarkan tingkat kemampuan yang berbeda-beda dalam kelompok kecil untuk bekerja sama mencapai tujuan belajar.

Menurut Slavin (Eggen dan Don, 2012: 144) mengatakan bahwa "STAD merupakan sebuah strategi pembelajaran kooperatif yang memberi tim berkembang majemuk latihan 
untuk mempelajari konsep dan keahlian". Secara umum ada lima komponen utama dalam model pembelajaran STAD yaitu (1) presentasi kelas, (2) kerja tim, (3) kuis, (4) penskoran, dan (5) pemberian penghargaan.

Berdasarkan uraian di atas, maka peneliti tertarik untuk melakukan penelitian dengan judul "Pengaruh model pembelajaran Student Teams Achievement Diviions (STAD) terhadap hasil belajar kognitif Siswa Kelas VIII Sekolah Menengah Pertama Negeri 7 Dedai pada Materi Sistem Pernapasan Manusia".

\section{METODE PENELITIAN Rancangan Penelitian}

Penelitian ini berbentuk penelitian eksperimen (Eksperimental Research). Menurut Sugiyono (2013: 107), "Metode penelitian eksperimen adalah metode penelitian yang digunakan untuk mencari pengaruh perlakuan tertentu terhadap yang lain dalam kondisi yang terkendalikan".

Pada penelitian eksperimen ini, peneliti juga harus membagi objek yang diteliti menjadi dua kelompok, yaitu kelompok treatment yang memperoleh perlakuan dan kelompok kontrol yang tidak memperoleh perlakuan. Jadi, penelitian eksperimen adalah cara yang digunakan peneliti untuk melakukan penelitian dengan adanya sebuah perlakuan (treatment).

Penelitian eksperimen yang digunakan adalah Quasi Experiment (eksperimen semu) dengan rancangan penelitian Nonequivalent Control Group Design. Menurut Sugiyono (2013: 114), "Quasi Experimental Design mempunyai kelompok kontrol tetapi tidak dapat berfungsi sepenuhnya untuk mengontrol variabel-variabel luar yang mempengaruhi pelaksanaan eksperimen". Sedangkan "Nonequivalent Control Group Design adalah desain yang hampir sama dengan pretest-posttest control group design, hanya pada desain ini kelompok eksperimen maupun kontrol tidak dipilih secara random" (Sugiyono, 2013: 116).

\section{Populasi dan Sampel Penelitian}

Populasi yang digunakan adalah siswa kelas VIII Sekolah Menengah Pertama Negeri 7 Dedai Tahun Pelajaran 2016/2017. Dengan sampelnya adalah kelas VIII B sebagai kelas eksperimen yang berjumlah 27 orang dan kelas VIII A Sekolah Menengah Pertama Negeri 7 Dedai sebagai kelas kontrol yang berjumlah 28 orang. Adapun teknik sampel yang digunakan dalam penelitian ini adalah Sampling jenuh. "Sampling Jenuh adalah penentuan sampel bila semua anggota populasi dipilih sebagai sampel dimana anggota populasi kurang dari 30 orang" (Martono, 2012: 74).

\section{Instrumen Penelitian}

Riduwan (2007: 69) mengatakan bahwa "instrumen pengumpulan data merupakan alat bantu yang digunakan oleh peneliti dalam kegiatan mengumpulkan agar kegiatan tersebut menjadi sistematis". Instrumen pengumpulan data yang digunakan dalam penelitian ini yakni: instrumen pengumpul dan instrumen pengukuran. Intrumen pengumpul yang digunakan dalam penelitan ini yakni: silabus, RPP, dan Lembar Kerja Siswa (LKS).

Sugiyono (2010: 193) mengatakan "instrumen pengukuran adalah alat bantu yang dipilih dan digunakan oleh peneliti untuk memperoleh hasil data dalam penelitian agar penelitian tersebut menjadi sistematis". Instrumen pengukuran yang digunakan dalam penelitian ini yakni: 1) lembar observasi, 2) lembar angket respon, 3) dan soal tes hasil belajar kognitif.

\section{Prosedur Penelitian}

Pada prosedur penelitian kali ini yang dilakukan adalah pertama melakukan pretest untuk kedua kelompok perlakuan tersebut, kedua adalah menerapkan teratment atau perlakuan pada kedua kelompok kelas tersebut sebanyak dua kali pertemuan dan ketiga adalah melakukan postes. Setalah itu data tersebut dilanjutkan untuk dianalisis. Adapun teknik pengumpulan data pada penelitian ini yaitu: 1) teknik observasi langsung, menurut Hadi (Sugiyono, 2013: 145) mengatakan bahwa "observasi merupakan suatu proses yang kompleks, tersusun dari berbagai proses biologis dan psikologis". 2) teknik pengukuran, Riduwan (2007: 83) mengatakan " teknik pengukuran adalah teknik pengumpulan data yang 
dapat dilakukan dengan menggunakan alat-alat tes, baik fisiologi maupun hasil belajar. 3) teknik komunikasi tidak langsung, 4) teknik studi dokumentasi.

\section{Teknik Analisis Data}

Analisis data merupakan suatu metode yang digunakan dalam mengolah data yang diperoleh selama penelitian yang selanjutnya dilakukan interpretasi terhadap hasil penelitian. 1) analisis lembar observasi pembelajaran, dimana analisis yang digunakan adalah skala Guttman. 2) analisis hasil tes, melalui beberapa tahapan yakni: a. pemberian skor, b. menentukan nilai, c. uji prasyarat, uji prasyarat meliputi: uji normalitas, uji homogenitas dan uji hipotesis. 3) analisis hasil angket.

\section{HASIL PENELITIAN}

\section{Hasil Kemampuan siswa di Kelas Eksperimen (Pretest dan Posttest)}

Sebelum sampel penelitian diberi perlakuan, terlebih dahulu guru memberikan tes awal (pretest) kepada siswa kelas VIII B sebagai kelas eksperimen yang berjumlah 27 orang. Ratarata pretest kelas eksperimen 38,89 dimana terdapat 27 siswa atau 100\% yang tidak memenuhi kriteria ketuntasan minimal (KKM).

Nilai rata-rata tes akhir (posttest) kelas ekpserimen sebesar 70,74 dimana terdapat 20 siswa atau $74,07 \%$ siswa yang memenuhi kriteria ketuntasan minimal (KKM) sedangkan 7 siswa atau 25,93\% siswa belum memenuhi kriteria ketuntasan minimal (KKM).

2. Hasil Kemampuan Siswa Sebelum dan Setelah Pembelajaran di Kelas Kontrol (Pretest dan Posttest)

Sebelum sampel penelitian diberikan perlakuan, terlebih dahulu guru memberikan tes awal (pretest) kepada siswa kelas VIII A Sekolah Menengah Pertama Negeri 7 Dedai sebagai kelas kontrol yang berjumlah 28 orang. Rata-rata pretest kelas kontrol 35 dimana terdapat 28 orang yang tidak memenuhi kriteria ketuntasan minimal (KKM).

Sedangkan nilai rata-rata posttest kelas kontrol sebesar 51 dimana terdapat 2 orang siswa atau 7,14\% siswa yang memenuhi kriteria ketuntasan minimal (KKM) sedangkan 26 siswa atau 92,86\% siswa belum memenuhi kriteria ketuntasan minimal (KKM).

3. Hasil Kemampuan Siswa di Kelas Eksperimen dan Kelas Kontrol

Sebelum dilakukan uji hipotesis, peneliti terlebih dahulu melakukan uji normalitas data. Uji normalitas data bertujuan untuk melihat apakah data berdistribusi normal atau berdistribusi tidak normal. Pada penelitian ini, uji normalitas data menggunakan uji chikuadrat. Hasil uji normalitas data dapat dilihat pada Tabel 1.

Tabel 1. Hasil Uji Normalitas Kelas Eksperimen dan Kelas Kontrol

\begin{tabular}{|c|c|c|c|c|c|c|}
\hline Data yang dikaji & $\bar{X}$ & SD & $\begin{array}{l}\mathrm{X}^{2}{ }_{\text {Hitun }} \\
\mathrm{g}\end{array}$ & $\mathbf{X}^{2}$ Tabel & A & Ket. \\
\hline Pretest Eksperimen & 38,91 & 10,62 & 11,238 & 7,81 & $\begin{array}{l}0,0 \\
5\end{array}$ & Tidak Normal \\
\hline Pretest Kontrol & 35,29 & 7,74 & 1,109 & 7,81 & $\begin{array}{l}0,0 \\
5\end{array}$ & Normal \\
\hline \multirow{2}{*}{$\begin{array}{l}\text { Posttest } \\
\text { Eksperimen } \\
\text { Posttest Kontrol }\end{array}$} & 69,85 & 9,16 & 2,696 & 7,81 & $\begin{array}{l}0,0 \\
5\end{array}$ & Normal \\
\hline & 51,18 & 9,69 & 5,4384 & 7,81 & $\begin{array}{l}0,0 \\
5\end{array}$ & Normal \\
\hline
\end{tabular}

Selanjutnya peneliti melakukan uji homogenitas data, uji homogenitas data dalam penelitian ini menggunakan uji F. Hasil uji homogenitas data dapat dilihat pada Tabel 2. 
Tabel 2. Hasil Uji Homogenitas Pretest dan Posttest Kelas Eksperimen dan Kelas Kontrol

\begin{tabular}{llllll}
\hline No & Data yang Diuji & $\mathbf{S}^{2}$ & $\mathbf{F}_{\text {hitung }}$ & $\mathbf{F}_{\text {tabel }}$ & Ket. \\
\hline \multirow{2}{*}{ 1. } & Pretest Eksperimen & 112,78 & \multirow{2}{*}{1,88} & 1,90 & Homogen \\
\cline { 2 - 3 } & Pretest Kontrol & 59,91 & & & \\
\multirow{2}{*}{2.} & $\begin{array}{l}\text { Posttest } \\
\text { Eksperimen }\end{array}$ & 83,91 & \multirow{2}{*}{1,12} & 1,90 & Homogen \\
\cline { 2 - 4 } & Posttest Kontrol & 93,89 & & & \\
\hline
\end{tabular}

Sedangkan uji hipotesis pada data posttest peneliti juga menggunakan uji parametrik yaitu Uji $t$. Sampel yang digunakan oleh peneliti sebanyak 27 siswa pada kelas eksperimen dan 28 siswa pada kelas kontrol. Hasil uji $t$ dapat dilihat pada Tabel 3.

\section{Tabel 3. Hasil Uji Hipotesis Posttest dengan Uji $t$}

\begin{tabular}{|c|c|c|c|c|c|}
\hline Kelas & $\mathbf{N}$ & $X$ & $Z_{\text {hitung }}$ & $Z_{\text {tabel }(\alpha=5 \%)}$ & Keterangan \\
\hline $\begin{array}{c}\text { Eksperimen } \\
\text { (VIII B) }\end{array}$ & 27 & 69,85 & 11,30 & 1,96 & $\begin{array}{c}\text { Terdapat perngaruh yang } \\
\text { signifikan penggunaan model } \\
\text { pembelajaran Student Teans } \\
\text { Achievement Divisions (STAD) } \\
\text { terhadap hasil belajar kognitif } \\
\text { siswa pada materi sistem } \\
\text { pernapasan manusia di kelas } \\
\text { VIII SMP Negeri } 7 \text { Dedai pada } \\
\text { materi sistem pernapasan } \\
\text { manusia }\end{array}$ \\
\hline
\end{tabular}

\section{PEMBAHASAN}

1. Kemampuan Siswa Sebelum dan Setelah Pembelajaran di Kelas Eksperimen (Pretest dan Posttest)

Analisis hasil pretest menunjukkan bahwa dari hasil pretest ditemukan kemampuan awal siswa dalam menjawab soal-soal yang mengukur kemampuan siswa pada kelas eksperimen masih rendah. Semua siswa belum memenuhi kriteria ketuntasan minimal (KKM). Sedangkan Hasil tes pada siswa kelas VIII B Sekolah Menengah Pertama Negeri 7 Dedai sebagai kelas eksperimen mengalami kenaikan nilai meskipun dengan kategori "Rendah".

2. Kemampuan Siswa Sebelum dan Setelah Pembelajaran di Kelas Kontrol (Pretest dan Posttest)

Analisis hasil pretest menunjukkan bahwa dari hasil pretest ditemukan kemampuan awal siswa dalam menjawab soal-soal yang mengukur kemampuan siswa pada kelas eksperimen masih rendah. Semua siswa belum memenuhi kriteria ketuntasan minimal (KKM). Sedangkan hasil posttest pada siswa kelas VIII A Sekolah Menengah Pertama Negeri 7 Dedai sebagai kelas kontrol mengalami kenaikan nilai meskipun masih dalam kategori "Rendah". 


\section{Perbedaan Kemampuan Siswa di Kelas Eksperimen dan Kelas Kontrol}

Berdasarkan hasil uji $t$ menunjukkan bahwa thitung $>t_{\text {tabel }}(1,891>1,96)$, maka $\mathrm{H}_{\mathrm{a}}$ diterima yaitu Terdapat pengaruh yang signifikan hasil belajar kognitif siswa antara kelas kontrol dan kelas eksperimen di kelas VIII SMP Negeri 7 Dedai pada materi sistem pernapasan manusia setelah pembelajaran (posttest). Hasil tersebut menunjukan bahwa antara kelas eksperimen dan kontrol terdapat pengaruh yang signifikan.

Selain itu, dilihat dari hasil yang diperoleh sangat sesuai dengan kegiatan pembelajaran yang diterapkan. Karena kegiatan pembelajaran dengan menggunakan model pembelajaran Student Teams Acheivement Divisions (STAD) memiliki ciri utama yaitu memotivasi siswa dalam satu kelompok untuk saling memberikan semangat, saling bekerja sama dan saling membantu untuk menuntaskan informasi atau keterampilan yang sedang dipelajari untuk menghadapi kuis individu.

Dengan kata lain model pembelajaran ini mengangkat satu masalah aktual sebagai satu pembelajaran yang menantang dan menarik minat siswa dalam proses pembelajaran.

Temuan ini sejalan dengan Slavin (Eggen dan Don, 2012: 144), yang menyatakan bahwa "STAD menepatkan pada partisipasi aktif peserta didik dalam kelompok belajar". Menurut Zulfiani (2012), mengemukakan "bahwa hasil belajar kognitif menggunakan pembelajaran kooperatif tipe STAD lebih tinggi dibandingkan dengan hasil belajar kognitif menggunakan metode ekspositori pada konsep ekosistem yang terintegrasi".

Selain didukung dari beberapa pendapat di atas, penelitian ini juga didukung oleh beberapa hasil penelitian sebelumnya yaitu hasil penelitian dari Risdiawati (2012) dengan menyatakan bahwa: Pembelajaran kooperatif tipe STAD dapat meningkatkan hasil belajar siswa.

Serta dari penelitian Harahap (2013) menyatakan bahwa: "aktifitas siswa yang mengikuti pembelajaran dengan model pembelajaran Student Teams Achievement Divisions (STAD) hal ini tidak terlepas dari pembelajaran yang memberikan kesempatan pada siswa untuk berdiskusi dan mencoba strategi yang ada dipikirannya dalam menyelesaikan suatu masalah".

Oleh karena itu, berdasarkan dari beberapa pendapat dan hasil penelitian yang pernah dilakukan, peneliti tertarik memadukan penelitian tersebut menjadi sebuah penelitian yang baru. Selain itu, setelah peneliti melakukan perhitungan secara statistik pada data posttest diperoleh hasil yang baik yaitu meningkatnya kemampuan siswa. Maka dari itu, dapat disimpulkan bahwa "Terdapat pengaruh yang signifikan hasil belajar kognitif siswa antara kelas kontrol dan kelas eksperimen di kelas VIII SMP Negeri 7 Dedai pada materi sistem pernapasan manusia".

\section{SIMPULAN}

Berdasarkan dari hasil penelitian yang telah dilaksanakan, dapat disimpulkan bahwa "Terdapat pengaruh yang signifikan penggunaan model pembelajaran Student Teams Achievement Divisions (STAD) terhadap hasil belajar kognitif siswa pada materi sistem pernapasan manusia di kelas VIII SMP Negeri 7 Dedai”. Berdasarkan sub masalah penelitian, maka dapat disimpulkan hal-hal sebagai berikut:

1. Kemampuan siswa sebelum penerapan model pembelajaran Student Teams Achievement Divisions (STAD) pada materi sistem pernapasan di kelas eksperimen diperoleh nilai ratarata 38,89 dengan kategori "Rendah" dan setelah diberi perlakuan dengan menerapkan pembelajaran model Student Teams Achievement Divisions (STAD) diperoleh nilai ratarata 70,74 dengan kategori "Rendah".

2. Kemampuan siswa sebelum pembelajaran konvensional pada materi sistem pernapasan manusia di kelas kontrol diperoleh nilai rata-rata 35 dengan kategori "Rendah" dan setelah diberi perlakuan dengan menerapkan pembelajaran konvensional diperoleh nilai rata-rata 51 dengan kategori "Rendah".

3. Terdapat pengaruh yang signifikan penggunaan model pembelajaran Student Teams Achievement Divisions (STAD) terhadap hasil belajar kognitif siswa pada materi sistem 
pernapasan manusia pada pengukuran posstest berdasarkan hasil nilai $t_{\text {hitung }}>t_{\text {tabel }}$ yaitu 6,981> 1,91 maka Ha diterima.

\section{REFERENSI}

Diah, I. P. (2011). Perbedaan Hasil Belajar Biologi Antara Siswa yang Diajarkan Melalui Pendekatan Kooperatif Teknik Student Team Achievement Divisions (STAD) dan Teknik Group Investigation (GI). Jurnal Pendidikan Biologi Fakultas IImu Tarbiyah dan Keguruan Universitas Islam Negeri Syarif Hidayatullah.

Dimyati dan Mudjiono (2013). Belajar dan Pembelajaran. Jakarta: Rineka Cipta.

Eggen, P dan Don, K. (2012). Strategi dan Model Pembelajaran. Jakarta: Indeks.

Laila, F. (2010). Pengaruh Model Pembelajaran Cooperative Tipe Group Investigation (GI) dan STAD Terhadap Prestasi Belajar Matematika Ditinjau dari Kemandirian Belajar Siswa. Jurnal Pendidikan Program Studi Pendidikan Matematika Universitas Sebelas Maret

Martono, N. (2012). Metode Penelitian Kuantitatif: Analisis Isi dan Analisis Data Sekunder. Jakarta: Rajawali Pers.

Nurmahni, H. (2013). Penerapan Model Pembelajaran Kooperatif Tipe STAD Terhadap Hasil Belajar Kognitif, Motivasi, dan Aktivitas Belajar Siswa pada Konsep Ekosistem Di MTsN Model Banda Aceh. Jurnal Pendidikan Biologi Stkip Bina Bangsa Getsempena Banda Aceh.

Purwanto. (2010). Metodologi Penelitian Kuantitatif Untuk Psikologi dan Pendidikan. Yogyakarta: Pustaka Belajar

Risdiawati, Y. (2012). Implementasi Model Pembelajaran Kooperatif Tipe Student Teams Achievement Divisions (STAD) Untuk Meningkatkan Motivasi dan Hasil Belajar Akuntansi Siswa Kelas XI IPS 4 SMA Negeri 1 Imogiri Tahun Ajaran 2011/2012. Jurnal Pendidikan Program Studi Pendidikan Akuntansi Fakultas Ekonomi Akuntansi Universitas Negeri Yogyakarta.

Sudjana, N. (2009). Penilaian Hasil Proses Belajar Mengajar. Bandung: Remaja Rosdakarya. Sugiyono. (2010). Metode Penelitian Kuantitatif Kualitatif dan R\&D. Bandung: Alfabeta.

Sugiyono. (2013). Metode Penelitian Kuantitatif Kualitatif dan R\&D. Bandung: Alfabeta.

Trianto. (2012). Model Pembelajaran Terpadu. Jakarta: Bumi Aksara. 
Undang-Undang RI. (2003). Sistem Pendidikan Nasional, Jakarta

Wahyuli, E. B. (2011). Penerapan Model Pembelajaran Kooperatif Tipe Student TeamsAchievement Divisions (STAD) untuk Meningkatkan Pemahaman Konsep Matematika pada Materi Persamaan dan Pertidaksamaan Kuadrat pada Peserta Didik Kelas X Teknik Komputer Jaringan (TKJ) di SMK 45 Wonosari. Fakultas Matematika dan IImu Pengetahuan Alam Universitas Negeri Yogyakarta. 